\title{
Spinal Cord Hamartoma
}

National Cancer Institute

\section{Source}

National Cancer Institute. Spinal Cord Hamartoma. NCI Thesaurus. Code C6815.

A hamartoma that occurs in the spinal cord. 